\title{
Introduction to the Special Section
}

\author{
Miklós Rosta \\ Associate Professor, Department of Comparative and Institutional Economics, Corvinus \\ University Budapest \\ Email: miklos.rosta@uni-covinus.hu
}

Professor Balázs Hámori celebrated his $70^{\text {th }}$ birthday in May 2016, and a conference was organized in his honour at Corvinus University of Budapest. Professor Hámori has been a distinguished professor and leader at Corvinus University and its Department of Comparative and Institutional Economics for many decades. During his career, he has contributed significantly to various fields of economics such as institutional economics, comparative economics, political economy, and behavioural economics. Professor Hámori can unquestionably credited be with introducing institutional economics to the Hungarian academic community, and he also wrote a series of seminal papers on behavioural economics. His research has contributed profoundly to our knowledge of the innovative capabilities of small- and medium-size enterprises, and he has deservedly won the admiration of his fellow economists for mapping the institutional environment that determined the emergence of a knowledge-based economy in Hungary.

This brief introduction reflects the colourful tapestry of Balázs Hámori’s many and wideranging interests within the field of economics. His oeuvre is a clear testimony to the fact that he did not commit himself to one particular methodology or trend in economics and that he has always been open to familiarising himself with new approaches and methods, as well as applying them.

Professor Hámori's community-building skills are well known and acknowledged. Countless young researchers started their careers in the research groups he had established. At the conference celebrating his birthday, his colleagues and friends presented their research findings that are bound by many strands to Professor Hámori's academic oeuvre. These presentations were the springboards for the papers that are published in this special section. While the articles cover almost all fields of Professor Hámori's research activities, they nonetheless share one common strand: all of them focus on the role of institutions and institutional change, exploring how institutions affect human behaviour in different situations. One of the key concepts, which appears in many papers, is trust. The role of trust in institutional change and its role in the transformation of economic and political systems is unquestionable. The other main theme that runs through most papers is innovation. This is hardly surprising, given that innovation can be conceptualised as the engine of institutional change.

The papers collected in the following special section demonstrate that crucial questions in economics and in the other social sciences can only be meaningfully approached by interdisciplinary methods. This colourful, interdisciplinary approach characterises the papers as well as the works of Professor Hámori. 
The first paper, written by Dóra Györffy, professor at Corvinus University Budapest and Pázmány Péter Catholic University, explores how trust is embedded in the field of comparative economics. After offering a precise definition of the concept of trust, she highlights how the study of trust is essential to economics, even if there is always room for improvement in defining and measuring its role. Comparative economics, and the analysis of the economic and political processes in the Central and Eastern European region in particular, has an enormous potential in contributing to the role of trust in economics.

Bruno Dallago, professor at the University of Trento, examines whether European Integration can be successful in a Europe where there are many varieties of capitalism. His conclusion is that in order to achieve a stronger European integration, we need to build trust between member states and not to strive for an exclusive economic system.

Barna Bakó and Péter Isztin, both from the Department of Microeconomics at Corvinus University, look at the role of supernatural beliefs in incentivising "good" behaviour among children by parents. Using game theory modelling, they focus on the time inconsistencies in parents' behaviour when trying to encourage their children's good behaviour by alluding to presents received from Santa Claus (a supernatural belief). The theoretical model can be expanded to analyse social relationships as well.

Katalin Szabó, professor emerita at Corvinus University, focuses on the process of radical institutional change in the $21^{\text {st }}$ century and the driver of this process, namely institutional entrepreneurs. In her thought-provoking and exciting paper, Professor Szabó looks at the institutional changes and innovations inspired by the new sharing economy model, while seeking an answer to the question of what kind of factors influence these processes.

Péter Gedeon, professor at the Department of Comparative and Institutional Economics of Corvinus University, explores the associations between the economic and political system of post-socialist countries using the approach of political economy. His article provides a sound theoretical springboard for interpreting the transformation of these systems. His principal claim is that a deeper analysis of the competition between political parties is needed for understanding why the institutions of western-type democracies and market economies have become distorted in this region.

The papers collected here are our tribute to Balázs Hámori. We wish him many years of exciting and challenging work and good health on his $70^{\text {th }}$ birthday! 